\title{
Study on Production Regulation of Reservoir under Different Demand
}

\author{
Jie Tan*, Enhui Sun, Wei Wang, Jingmin Guo, Wei Yang \\ Bohai Oilfield Research Institute of CNOOC Ltd.-Tianjin Branch, Tianjin, China \\ Email: ^tanjie3@cnooc.com.cn
}

How to cite this paper: Tan, J., Sun, E.H., Wang, W., Guo, J.M. and Yang, W. (2019) Study on Production Regulation of Reservoir under Different Demand. Journal of Power and Energy Engineering, 7, 39-49. https://doi.org/10.4236/jpee.2019.77004

Received: July 1, 2019

Accepted: July 28, 2019

Published: July 31, 2019

Copyright $\odot 2019$ by author(s) and Scientific Research Publishing Inc. This work is licensed under the Creative Commons Attribution International License (CC BY 4.0).

http://creativecommons.org/licenses/by/4.0/

\begin{abstract}
Natural gas production is related to the demand for gas, which is low in summer and high in winter. While the gas storage is still being demonstrated and constructed, oil and gas fields should formulate and implement production control schemes suitable for gas reservoirs. The realization of natural gas production can not only meet the demand of gas consumption, but also ensure the scientific and efficient development of gas reservoirs, and meet the needs of dynamic analysis of gas reservoirs at different development stages and scientific research of gas reservoirs. In this paper, KAPPA Workstation 5.20 software is used to determine the inflow dynamic model of a single well. The nodal method is used to determine the reasonable production and peak shaving capacity in combination with the critical fluid carrying capacity of gas wells and the erosion rate of gas wells. The reasonable production allocation in each period, i.e. the production control scheme, is obtained. It solves the scientific and efficient development of natural gas in $\mathrm{X}$ gas field, which is still under the construction of gas storage, and provides guidance for gas reservoir development management and regulation.
\end{abstract}

\section{Keywords}

Gas Reservoir, Regulation of Production, Erosion Velocity, The Critical Liquid Carrying Capacity of Gas Well, Reasonable Production

\section{Introduction}

In order to coordinate the contradiction between gas field production and market gas demand, most of the domestic and foreign countries have achieved effective solutions through the construction of some spare capacity, underground gas 
storage and introduction of LNG [1]-[6]. However, the productivity evaluation data of gas wells in different production stages of $\mathrm{X}$ gas reservoir is not enough, and it is difficult to determine the reasonable production and peak shaving production of gas wells. In order to meet the downstream gas demand, it is difficult for some gas wells to shut in the well on time or the time of complex pressure test is not enough, the percolation parameters of the gas reservoir cannot be accurately calculated, and the gas well dynamic analysis lacks the necessary well test data. In the case of imperfect downstream gas supply system, on the basis of recognizing the current production capacity and its change rule of the gas reservoir, it is necessary to study and determine the stable production capacity of the gas reservoir under different production capacity conditions, so as to clarify the peak regulation capacity of the upstream gas field, optimize the production regulation scheme of the gas reservoir and ensure the scientific and efficient development of the gas field under the condition of meeting the downstream gas demand. This paper takes the gas reservoir as the research object, based on the percolation theory, well test analysis theory and material balance principle of the gas reservoir, and through the analysis of the production constraints of gas wells in the gas reservoir, obtains the production regulation scheme, which provides guidance and technical support for the development management and regulation of the gas reservoir.

\section{Reasonable Production Analysis of Gas Wells}

Gas wells are affected by many factors in the production process, such as gas well productivity, production decline, minimum liquid carrying speed, gas erosion on tubing and string and other factors will limit the production of gas wells.

\subsection{Evaluation of Gas Well Productivity by Unsteady Flow Productivity Analysis}

The production capacity analysis method of unsteady flow considers the coupling effect of gas reservoir and wellbore. It uses the production dynamic data of gas well (daily monthly production, oil pressure, flow pressure, static pressure, production hours), through the theory of unsteady seepage and material balance equation, and takes the formation seepage well bore flow well orifice throttling as the production system for overall analysis. Considering not only the percolation characteristics of gas wells, but also the flow of wellbore, the long-term dynamic analysis and prediction of gas well productivity can be realized, avoiding the limitations of traditional semi empirical and semi theoretical analysis methods.

In this study, in kappa workstation 5.20 software, first use the TOPAZE module to fit the production dynamic data (Figure 1), take the formation seepage, wellbore flow and wellhead throttling as the production system for overall analysis, and get the parameters of a single well, such as daily production, oil pressure, 
flow pressure, static pressure, production hours, etc. Combined with Saphir module, IPR curves of gas wells in different production periods are obtained to study the current inflow performance of single wells in each gas reservoir (Figure 2).

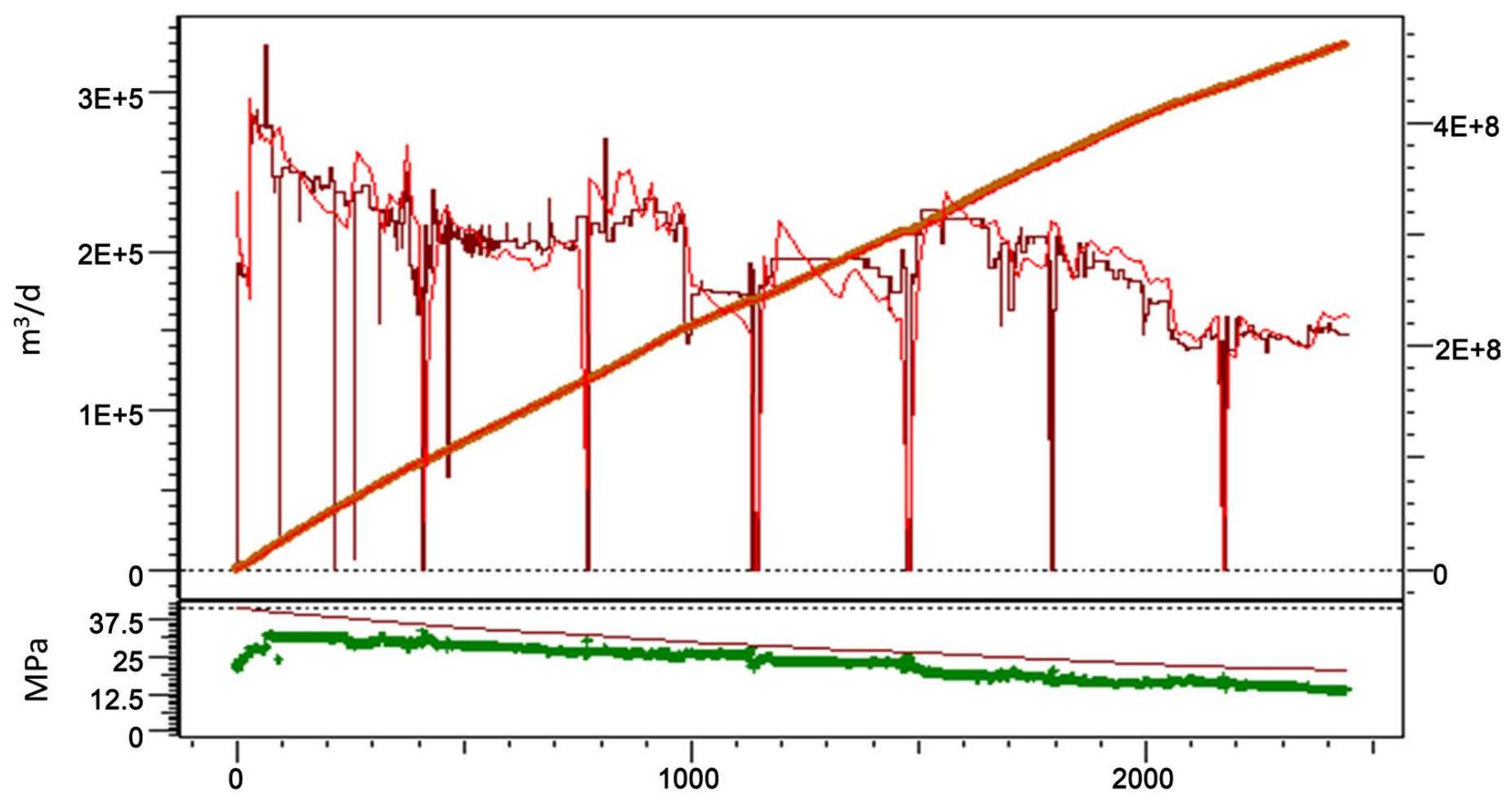

Gas flow rate, $\mathrm{m}^{3} / \mathrm{d}$. Gas volume, $\mathrm{m}^{3}$. Pressure, MPa-Time, day.

Figure 1. Fitting chart of gas well production history.

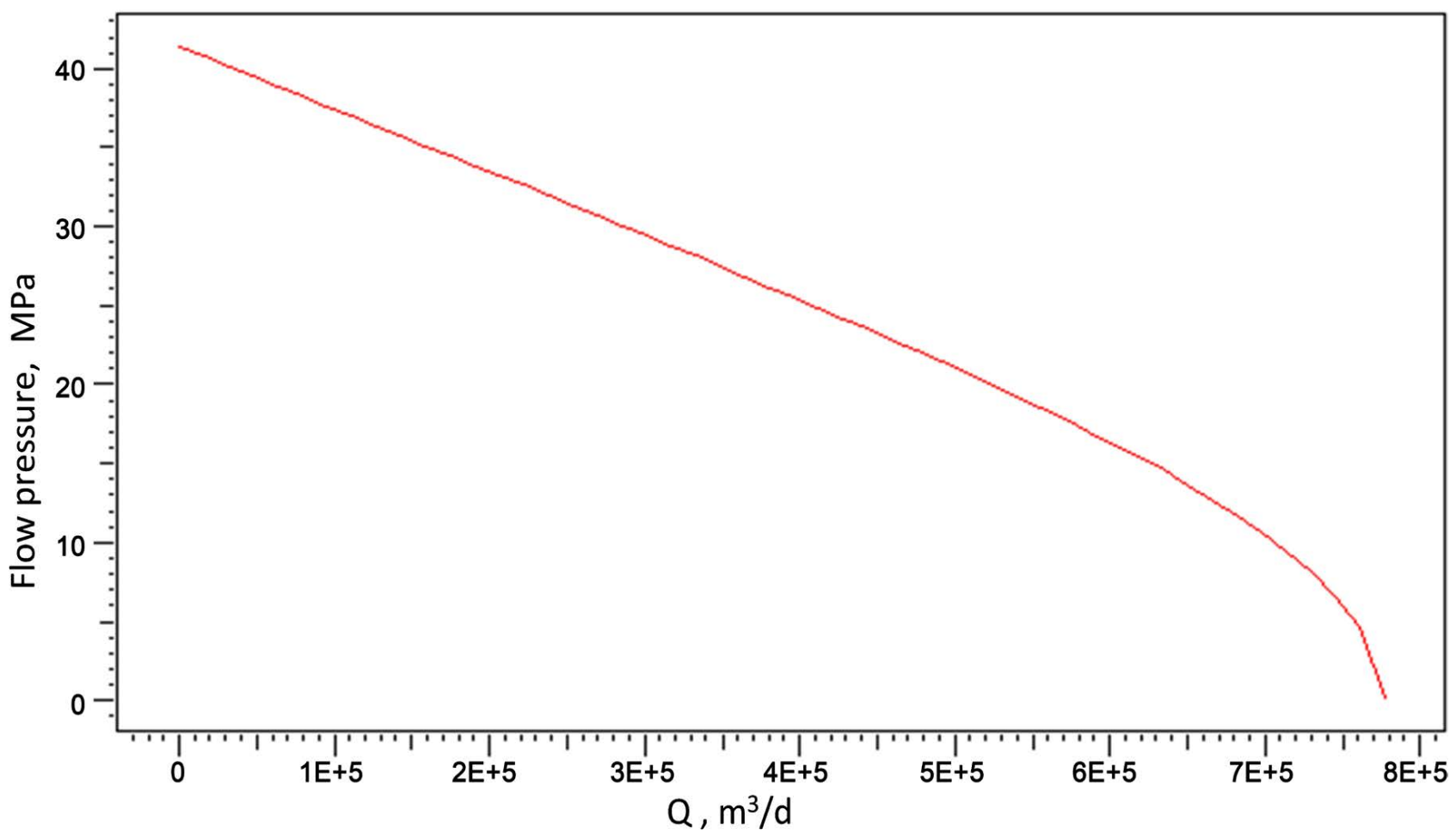

Figure 2. IPR curve of gas well. 


\subsection{Study on the Law of Production Capacity Decline}

Using APRs production decline analysis to study the law of production decline [7] [8] [9] [10]:

$$
\frac{\alpha}{\alpha_{i}}=\left(\frac{Q_{A O F}}{Q_{A O F i}}\right)^{n}
$$

where, $\alpha$ is capacity decline rate, $\alpha_{i}$ is initial production decline rate, $Q_{A O F i}$ is initial production capacity, $n$ is decline index.

When $n=0, a=a_{i}=$ const, decrement for index (normal decrement).

When $n=1, a=a_{i}\left(Q_{A O F} / Q_{A O F i}\right)$, decreasing for harmony.

When $0<n<1, \quad a=a_{i}\left(Q_{A O F} / Q_{A O F i}\right)^{n}$, it's called decrement.

Specifically, when $n=-1$, it is called linear decrement.

When $n=0.5$, it is called decrement.

\subsubsection{Exponential Decline Analysis}

For exponential decrement $n=0, \alpha=\alpha_{i}=$ constant .

According to the definition of decline rate, when the law of production capacity decline satisfies the exponential decline of $n=0$, i.e. $\alpha_{i}=$ constant, we can get:

$$
-\frac{1}{Q_{A O F}} \mathrm{~d} Q_{A O F}=\alpha \mathrm{d} t
$$

Definite integral on both sides $-\int_{Q_{A O F i}}^{Q_{A O F}} \frac{\mathrm{d} Q_{A O F}}{Q_{A O F}}=\alpha \int_{0}^{t} \mathrm{~d} t$ can get:

$$
\ln \left(Q_{A O F} / Q_{A O F i}\right)=-\alpha t \text { or } Q_{A O F}=Q_{A O F i} \mathrm{e}^{-\alpha t}
$$

In the same way, according to the definition, we can get the different expressions of the production decline rate $\alpha_{p}$ at the pressure level, $\alpha_{p 2}$ at the pressure square and $\alpha_{R}$ at the production degree under the exponential decline

$$
\left\{\begin{array}{l}
Q_{A O F}=Q_{A O F i} \mathrm{e}^{\alpha_{p}\left(P-P_{i}\right)} \\
Q_{A O F}=Q_{A O F i} \mathrm{e}^{\alpha_{p 2}\left(P^{2}-P_{i}^{2}\right)}
\end{array}\right.
$$

\subsubsection{Harmonic Decline Analysis}

When the law of production capacity decline satisfies the harmonic decline of $n$ $=1, \alpha=\alpha_{i}\left(Q_{A O F} / Q_{A O F i}\right)$, we can get:

$$
-\frac{1}{Q_{A O F}} \frac{\mathrm{d} Q_{A O F}}{\mathrm{~d} t}=\alpha_{i} \frac{Q_{A O F}}{Q_{A O F i}}
$$


Take the definite integral on both sides $-\int_{Q_{i}}^{Q} \frac{\mathrm{d} Q_{A O F}}{Q_{A O F}^{2}}=\frac{\alpha_{i}}{Q_{A O F i}} \int_{0}^{t} \mathrm{~d} t$ to get:

$$
\begin{gathered}
\frac{1}{Q_{A O F}}=\frac{1}{Q_{A O F i}}+\frac{\alpha_{i}}{Q_{A O F i}} t \\
=\frac{1+\alpha_{i} t}{Q_{A O F i}} \\
\text { or } \ln \left(\frac{Q_{A O F i}}{Q_{A O F}}\right)=\ln \left(1+\alpha_{i} t\right)
\end{gathered}
$$

In the same way, the different expressions of the pressure level production decline rate $\alpha_{P}$ and the pressure square production decline rate $\alpha_{P^{2}}$ under harmonic decline are obtained:

$$
\left\{\begin{array}{l}
\ln \left(\frac{Q_{A O F i}}{Q_{A O F}}\right)=\ln \left[1-\alpha_{P i}\left(P-P_{i}\right)\right] \\
\ln \left(\frac{Q_{A O F i}}{Q_{A O F}}\right)=\ln \left[1-\alpha_{P^{2} i}\left(P^{2}-P_{i}^{2}\right)\right]
\end{array}\right.
$$

\subsubsection{Hyperbolic Decline Analysis}

When the production capacity decline law satisfies the hyperbolic decline of $0<n<1, \quad \alpha=\alpha_{i}\left(Q_{A O F} / Q_{A O F i}\right)^{n}$, we can get

$$
\begin{aligned}
& -\frac{1}{Q_{A O F}} \frac{\mathrm{d} Q_{A O F}}{\mathrm{~d} t} \\
& =\alpha_{i}\left(\frac{Q_{A O F}}{Q_{A O F i}}\right)^{n}
\end{aligned}
$$

Separate variables $-\int_{Q_{A O F i}}^{Q_{A O F}} \frac{1}{Q_{A O F}^{n+1}} \mathrm{~d} Q_{A O F}=\frac{\alpha_{i}}{Q_{A O F i}^{n}} \int_{0}^{t} \mathrm{~d} t$ and take definite integral on both sides:

$$
\begin{gathered}
\frac{1}{Q_{A O F}^{n}}-\frac{1}{Q_{A O F i}^{n}}=\frac{n \alpha_{i}}{Q_{A O F i}^{n}} t \\
Q_{A O F}=Q_{A O F i} /\left(1+n \alpha_{i} t\right)^{1 / n}
\end{gathered}
$$

In the same way, we can get different expressions about the decline rate of productivity in the pressure level, the decline rate of productivity in the pressure square and the production degree under the hyperbolic decline:

$$
\left\{\begin{array}{l}
Q_{A O F}=\frac{Q_{A O F i}}{\left[1-n \alpha_{P i}\left(P-P_{i}\right)\right]^{1 / n}} \\
Q_{A O F}=\frac{Q_{A O F i}}{\left[1-n \alpha_{p^{2} i}\left(P^{2}-P_{i}^{2}\right)\right]^{1 / n}}
\end{array}\right.
$$


By using the method of judging production decline type, the methods of judging production decline type (i.e. determining decline parameters I and N) of gas reservoir (well) include: graphic method, trial and error method, curve displacement method, binary linear regression method, typical curve fitting method [7], etc.

Considering that there is no obvious relationship between production capacity change and production time in actual production, trial and error method is used to determine formation pressure level and pressure square decline type (Figure 3).

According to production capacity decline study, future capacity can be predicted. Take 1/3 1/4 of the production capacity as one of the current reasonable production reference values, so as to predict the reasonable production capacity.

\subsubsection{Critical Liquid Carrying Capacity}

The minimum velocity of fluid flow from the wellbore to the surface is called the minimum fluid carrying velocity or critical production. It is of great significance to keep the gas well production greater than the minimum liquid carrying speed for improving the recovery rate of gas reservoir, especially for water producing gas reservoir.

According to Coleman model [11] [12] [13] [14], the wellhead pressure of liquid well is generally lower than $3.4475 \mathrm{mpa}$. Coleman deduced the formula of critical liquid carrying velocity of low pressure gas well (12):

$$
u_{c r}=4.45\left[\frac{\sigma\left(\rho_{1}-\rho_{g}\right)}{\rho_{g}^{2}}\right]^{0.25}
$$

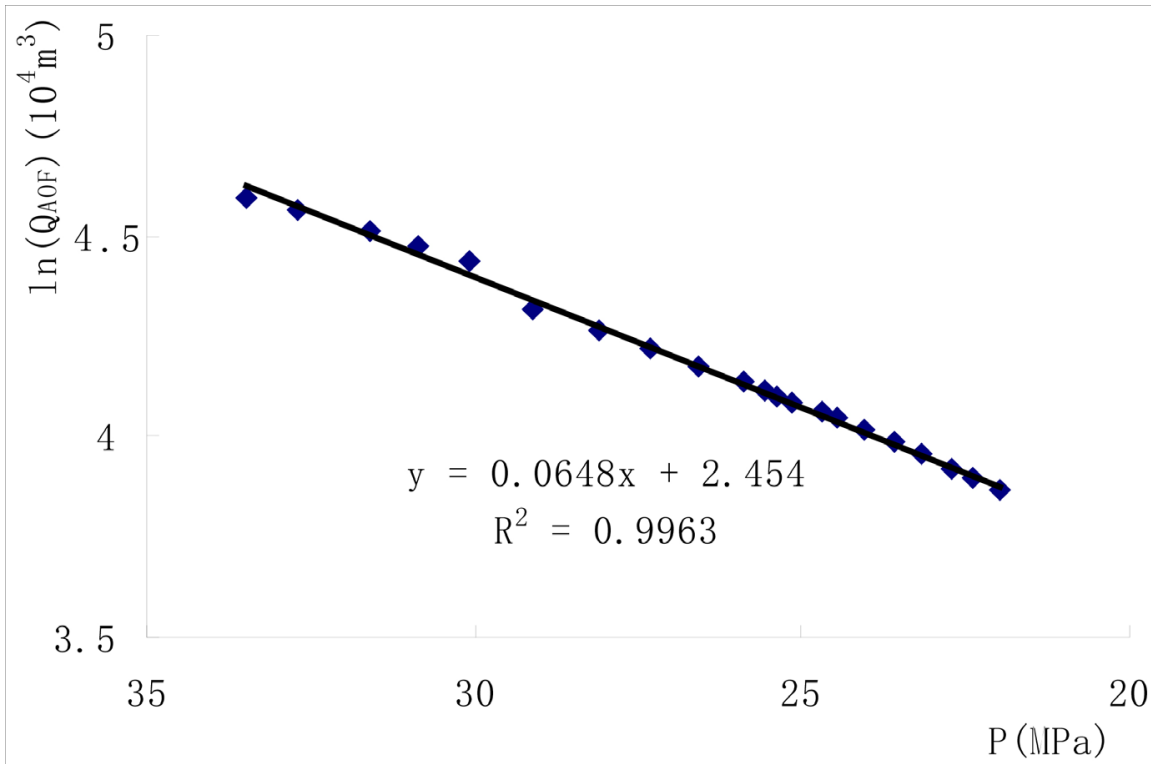

Figure 3. Pressure level production decline curve. 
where, $u_{c r}$ is Critical velocity of liquid carrying in gas wells, m/s. $\sigma$ is Air-water interfacial tension, N/m. $\rho_{1}$ is Density of liquids, $\mathrm{kg} / \mathrm{m}^{3} . \rho_{g}$ is Density of gases, $\mathrm{kg} / \mathrm{m}^{3}, \quad \rho_{g}=3.4844 \times 10^{3} \frac{\gamma_{g} p}{Z T}, \quad \sigma=60 \times 10^{-3} \mathrm{~N} / \mathrm{m}$.

\subsection{Erosion Velocity of Gas Wells}

Erosion velocity is the maximum limit flow rate to avoid the erosion effect of high-speed flowing gas in wellbore on tubing and tubing string. The safe flow rate of erosion can be calculated by formula (1) Beggs [15] [16] [17]:

$$
\left\{\begin{array}{l}
V_{e}=\frac{C}{\rho_{g}^{0.5}} \\
q_{e}=40538.17 \times D^{2}\left(\frac{p_{w h}}{Z T \gamma_{g}}\right)^{0.5}
\end{array}\right.
$$

where $V_{e}$ is erosion velocity, $\mathrm{m} / \mathrm{s} . \quad C=122 . \rho_{g}$ is gas density, $\mathrm{kg} / \mathrm{m}^{3} ; q_{e}$ is Erosion discharge, $\mathrm{m}^{3} / \mathrm{d} ; A$ is Tubing section area, $\mathrm{m}^{2} . p_{w h}$ is wellhead pressure, $\mathrm{MPa} ; T$ is wellhead temperature, $\mathrm{K} ; Z$ is deviation coefficient; $\gamma_{g}$ is relative density of natural gas.

\section{The Establishment of the Mathematical Model for the Optimization of the Reasonable Production of Gas Reservoir}

The reasonable production of gas well is one of the important indexes of gas reservoir development, which is of great significance to the efficient development of gas reservoir. The determination of reasonable production of gas wells is related to gas reservoir reserves, reservoir properties and parameters, well bore structure, stable production period, economic benefits and other factors. According to the specific situation of gas reservoir, sometimes the reasonable production of gas well can be determined according to single factor, sometimes multiple factors should be considered to determine the reasonable production comprehensively, but the general principle is that the reasonable production must follow the principle of resource protection and environmental protection to ensure the stable and safe gas supply of gas well.

In order to realize the reasonable production scheduling of gas reservoir, the overall scheme of production regulation is studied. According to the production constraints, the distribution production of gas reservoir is $q_{i}$, and the single well production of gas reservoir is $q_{i j}$. The minimum fluid carrying capacity of the gas reservoir is $q_{\text {mini }}$, and the erosion velocity of the gas reservoir is $q_{e i}$. In this paper, assuming that a single well is assigned production according to the current maximum production capacity, the assigned production index is $\lambda_{i j}$, and the switch well is represented by $\eta_{i j}$, the assigned production model is established. 


$$
\begin{aligned}
& \text { Min } \eta_{i j}\left(q_{e i}, q_{\min i j}, q_{\max i j}, r_{D}, r_{W}, P_{w f}(\min ), G_{P}, P_{w f}, P, \lambda_{i j}\right)
\end{aligned}
$$

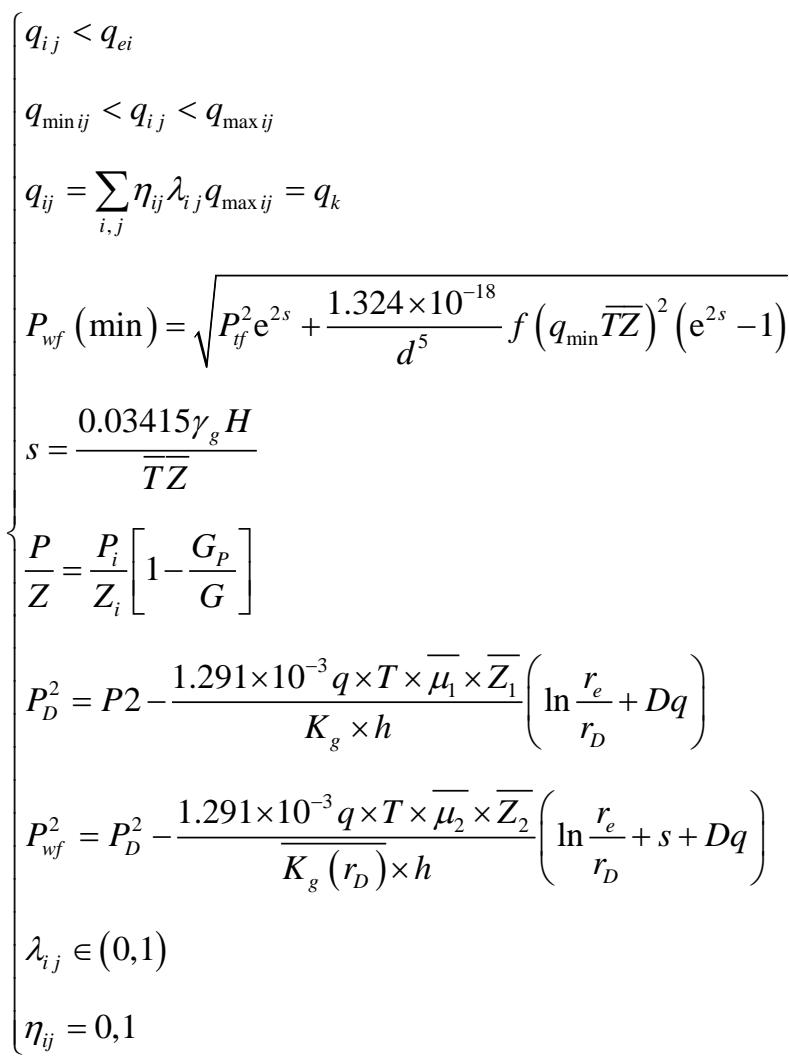

\section{Example Analysis}

Take $\mathrm{x}$ gas reservoir as an example. According to the demand of different months, make the reasonable production of each well in different months (Table 1). According to the model, the gas distribution of single well in each period can be calculated. Table 2 below shows the distribution results of low peak period (July) calculated by the model.

\section{Conclusions}

Through the study of production regulation of $\mathrm{X}$ gas reservoir, the following conclusions and understandings have been obtained:

1) The gas well productivity is obtained by the evaluation method of non shut in productivity.

2) By defining the production decline rate, we can calculate the law of production decline in different periods and study the law of production decline. The law of single well production decline is mainly linear decline.

Table 1. Actual monthly demand.

\begin{tabular}{ccccccccccccc}
\hline Mouth & $\mathbf{1}$ & $\mathbf{2}$ & $\mathbf{3}$ & $\mathbf{4}$ & $\mathbf{5}$ & $\mathbf{6}$ & $\mathbf{7}$ & $\mathbf{8}$ & $\mathbf{9}$ & $\mathbf{1 0}$ & $\mathbf{1 1}$ & $\mathbf{1 2}$ \\
\hline $\begin{array}{c}\text { Gas demand } \\
10^{4} \mathrm{~m}^{3}\end{array}$ & 19,840 & 17,920 & 19,840 & 13,500 & 13,950 & 12,000 & 10,035 & 10,850 & 11,400 & 14,880 & 13,500 & 15,500 \\
\hline
\end{tabular}


Table 2. Production allocation results of single well in low peak period (July) of production control plan for X gas reservoir.

\begin{tabular}{|c|c|c|c|c|c|c|c|}
\hline Well number & $\begin{array}{c}\text { Qmax } \\
10^{4} \mathrm{~m}^{3} / \mathrm{d}\end{array}$ & $\begin{array}{l}\text { Erosion elocity } \\
10^{4} \mathrm{~m}^{3} / \mathrm{d}\end{array}$ & $\begin{array}{l}\text { Critical liquid } \\
\text { carrying } \\
\text { capacity } \\
10^{4} \mathrm{~m}^{3} / \mathrm{d}\end{array}$ & $\begin{array}{l}\text { Allocation } \\
\text { coefficient }\end{array}$ & $\begin{array}{c}\text { Yield } \\
\text { distribution } \\
10^{4} \mathrm{~m}^{3} / \mathrm{d}\end{array}$ & $\begin{array}{c}\text { Shut in time } \\
\text { d }\end{array}$ & $\begin{array}{c}\text { Monthly } \\
\text { cumulative } \\
\text { production } \\
10^{4} \mathrm{~m}^{3}\end{array}$ \\
\hline $\mathrm{H} 2$ & 35.50 & 37.75 & 5.78 & 0.74 & 26.38 & 5.00 & 672.66 \\
\hline $\mathrm{H} 3$ & 29.70 & 35.41 & 5.44 & 0.81 & 24.16 & 5.00 & 616.10 \\
\hline H5 & 36.10 & 35.41 & 5.44 & 0.84 & 30.47 & 5.00 & 776.99 \\
\hline H6 & 33.70 & 37.75 & 5.78 & 0.75 & 25.27 & 0.00 & 770.79 \\
\hline $\mathrm{H} 1$ & 32.16 & 34.93 & 5.38 & 0.81 & 26.12 & 5.00 & 666.06 \\
\hline M2 & 19.20 & 46.31 & 6.96 & 0.53 & 10.25 & 0.00 & 312.63 \\
\hline M3 & 73.60 & 82.87 & 8.85 & 0.60 & 44.47 & 5.00 & 1133.96 \\
\hline M4 & 52.80 & 76.18 & 8.18 & 0.39 & 20.70 & 0.00 & 631.35 \\
\hline M1 & 94.00 & 75.11 & 8.08 & 0.72 & 67.26 & 5.00 & 1715.07 \\
\hline $\mathrm{P} 1$ & 13.30 & 38.63 & 5.84 & 0.58 & 7.69 & 6.00 & 188.31 \\
\hline $\mathrm{P} 2$ & 5.92 & 34.41 & 5.20 & 0.41 & 2.40 & 0.00 & 73.25 \\
\hline P3 & 22.90 & 34.71 & 5.25 & 0.21 & 4.71 & 0.00 & 143.60 \\
\hline P7 & 18.50 & 34.64 & 5.24 & 0.58 & 10.72 & 6.00 & 262.65 \\
\hline P9 & 2.94 & 27.43 & 4.13 & 0.48 & 1.40 & 0.00 & 42.69 \\
\hline P6 & 28.18 & 32.99 & 4.99 & 0.58 & 16.25 & 6.00 & 398.20 \\
\hline P5 & 18.60 & 34.17 & 5.17 & 0.72 & 13.44 & 6.00 & 329.37 \\
\hline D1 & 25.90 & 45.63 & 6.97 & 0.35 & 9.07 & 5.00 & 231.31 \\
\hline D4 & 12.20 & 46.55 & 7.11 & 0.55 & 6.67 & 5.00 & 170.14 \\
\hline D5 & 12.40 & 50.96 & 7.75 & 0.73 & 9.07 & 5.00 & 231.35 \\
\hline D6 & 24.11 & 57.64 & 8.68 & 0.42 & 10.04 & 5.00 & 256.08 \\
\hline D3 & 5.45 & 45.63 & 6.97 & 0.46 & 2.53 & 5.00 & 64.54 \\
\hline D7 & 18.10 & 62.54 & 9.31 & 0.15 & 2.68 & 5.00 & 68.45 \\
\hline D8 & 22.00 & 64.95 & 9.96 & 0.50 & 10.97 & 5.00 & 279.73 \\
\hline Sum. & & & & & & & $10,035.28$ \\
\hline
\end{tabular}

3) Through the analysis and evaluation of production constraints in terms of gas well erosion velocity and critical liquid carrying capacity, the erosion velocity and critical liquid carrying capacity under different tubing sizes are obtained.

4) The optimization method is used to study the production control and es- 
tablish the optimization mathematical model, which can give the reasonable production of gas wells according to the demand and conditions of different periods.

\section{Conflicts of Interest}

The authors declare no conflicts of interest regarding the publication of this paper.

\section{References}

[1] Lu, J.L. (2009) Upstream Peaking Impact on the Gas Field Development. Natural Gas Industry, 29, 64-66.

[2] Wiik, J., Gjerde, J.O., Gjengedal, T., et al. (2002) Steady State Power System Issues When Planning Large Wind Fauns. IEEE Power Engineering Society Winter Meeting, New York

[3] Cullender, M.H. (2004) The Isochronal Peribnnance Method of Deetnnining the Flow Characteristics of Gas well. Transactions of AIME, 204, 137-142. https://doi.org/10.2118/330-G

[4] Kazt, D.L., Conrell, D., Kobayashi, R.K., et al. (1959) Hand Book of Natural Gas Engineering. McGraw-Hill Book Co., New York, 448-459.

[5] Ramey Jr., H.J. (1965) Non-Darcy Flow and Wellbore Storage Effects in Pressure Build-up and Draw-down of Gaswells. Journal of Petroleum Technology, 1058-PA, 225-233. https://doi.org/10.2118/1058-PA

[6] Wu, J.F., et al. (2007) Research Status and Development Trend of Domestic and Foreign Gas Storage Technology. Oil \& Gas Storage and Transportation, 26, 1-3.

[7] Cao, L. (2017) Research on Unsteady Percolation Theory and Rate Transient Analysis in Tight Gas Reservoirs. Sichuan Southwest Petroleum University, [Chengdu.

[8] Li, M., et al. (2002) Comparative Study of Continuous Liquid Carrying Model of Gas Well. Fault Block Oil and Gas Field, 9, 39-41.

[9] Ma, Y.X. (2017) Study on Pressure Sensitivity of Abnormal High Pressure Reservoirs in Dongfang X Gasfield.

[10] Xu, Y. and Ruan, M. (2001) A Practical Method of Production Decline Analysis of Gas Field. The Development of Production, 21, 85-87.

[11] Liu, C.X. (2018) Reasonable Developing Countermeasure and Its Effect Evaluation of the Bottom-Water Gas Reservoir in the Volcanic Rock of Block x in xs Gas Field. Petroleum Geology and Oilfield Development in Daqing, 37, 79-84.

[12] Liu, D.H. and Li, G.Y. (1990) Research on the Scale of Optimal Allocation of Gas Field Development Planning. Journal of Southwest Petroleum Institute, 12, 63-71.

[13] Shu, Z.Z., Du, Z.M., Liu, J.Y., et al. (2004) Prediction Method of Gas Well Production Performance. Natural Gas Industry, 24, 78-81.

[14] Zeng, M., Hu, N., Yin, X.H., et al. (2018) Evaluation on Development Technologies for Mono-Block Water-Bearing Gas Reservoirs. Sichuan Basin Natural Gas Exploration and Development, 41, 70-74. 
[15] Ming, R.Q., He, H.Q., Hu, Q.F., et al. (2018) A New Method to Predict Water Breakthrough Time in Condense Gas Reservoir with Bottom-Aquifer. Special Oil and Gas Reservoirs, 25, 99-103.

[16] Li, S.L. (2000) Natural Gas Engineering. Petroleum Industry Press, Beijing.

[17] Wu, H.B., He, Y., Zhou, Y., et al. (2009) Comparison and Selection of Natural Gas Peak Shaving Methods. Natural Gas and Oil, 27, 5-10. 